\title{
Prevalence of Adult Obesity in the Guadeloupean Diabetic Population
}

\author{
Koffi Dago Pierre, ${ }^{1, *}$, Deh Zhou Patricia ${ }^{2}$, El Mokhtari Mohammed ${ }^{3}$, Monteomo Gnate François ${ }^{4}$, \\ Kangambega Pauline ${ }^{3}$, Kouassi Franck ${ }^{1}$, Yao Assita ${ }^{1}$, Hue Adelaide ${ }^{1}$, Abodo Jacko Rhedoor ${ }^{1}$ \\ ${ }^{1}$ Department of Endocrinology - Diabetology, University Health Center of Yopougon, Abidjan, Côte d'Ivoire \\ ${ }^{2}$ Laboratory of Histology, Embryology and Cytogenetic, UFR-Medical Sciences, Felix Houphouët-Boigny University, Abidjan, Côte d'Ivoire \\ ${ }^{3}$ Department of Endocrinology - Diabetology, University Health Center of Pointe-à-Pitre, Guadeloupe, France \\ ${ }^{4}$ Laboratory of Physiology, Pharmacology and Pharmacopoeia, UFR-Nature Sciences, Nangui-Abrogoua University, Abidjan, Côte d'Ivoire
}

\section{Email address:}

akradag2004@gmail.com (K. D. Pierre)

${ }^{*}$ Corresponding author

\section{To cite this article:}

Koffi Dago Pierre, Deh Zhou Patricia, El Mokhtari Mohammed, Monteomo Gnate François, Kangambega Pauline, Kouassi Franck, Yao Assita, Hue Adelaide, Abodo Jacko Rhedoor. Prevalence of Adult Obesity in the Guadeloupean Diabetic Population. European Journal of Preventive Medicine. Vol. 5, No. 6, 2017, pp. 87-90. doi: 10.11648/j.ejpm.20170506.12

Received: September 30, 2017; Accepted: October 26, 2017; Published: November 20, 2017

\begin{abstract}
Obesity is defined by an increase in fat mass. Its prevalence in the diabetic population is unknown. The aim of this study is to determine the prevalence of obesity in the diabetic population. We conducted a descriptive cross-sectional study of adult diabetic patients followed in endocrinology consultation of University Teaching Hospital of Pointe -à- Pitre, GuadeloupeFrance during the period from October 2014 to November 2016. The present study comprised of a total of 385 type 2 diabetic subjects whose BMI was measured during the visit to the diabetic consultation. Respondents' height, weight, age and sex of diabetes were taken as the study variable. The prevalence of obesity was $43,40 \%$. The mean age of the patients was $60 \pm 10,9$ years. The peak; frequency of obesity was between 46 and 55 years. Obesity was significantly common in women $(60,5 \%)$ than men $39,5 \%)$ with a $p<0,05$. The proportion of obesity in female type 2 diabetes proportion $(60,5 \%)$ was comparatively higher than male (39,5\%). Occupation categories affected were represented by pensioners $18(10,6 \%)$, engineers $19(10,8 \%)$, 25 retired civil servants $(14,3 \%)$ and 50 housewives $(28,6 \%)$. Obesity is frequent in the diabetic population in Guadeloupe. It is therefore urgent to implement interventions more at risk to prevent, early detection of weight gain in diabetes.
\end{abstract}

Keywords: Prevalence, Obesity, Type 2 Diabetes, BMI

\section{Introduction}

Diabetes mellitus is one of the most common endocrine disorders in the world. The prevalence of diabetes has been increasing globally and the disease has become one of the major public health concerns. According to World Health Organization (WHO), diabetes affects more than 170 million people worldwide and the number will rise to 370 million by 2030, World health organization 2004. The recent update of WHO has updated that diabetes, hypertension and obesity are one of the top five continuing risk factors for cardiovascular deaths in the world, [25, 26].

Obesity is defined as an increase in fat mass resulting from defective regulation of energy balance. It is a chronic, multifactorial, spontaneously unfavorable evolution, more common in adults and children [11]. It is a wholly disease that affects the quality of life and is the source of somatic, psychological and social complications. Its management, difficult must register in time.

Obesity in persons with diabetes is associated with poorer control of blood glucose levels, blood pressure, and high serum cholesterol [16], placing patients at higher risk for both cardiovascular and microvascular disease $[2,4]$.

It does interfere with not only effective treatment of hyperglycemia, but also hypertension and dyslipidemia cardiovascular disease, cerebrovascular disease, hyperlipidemia, [12]. In addition to the increased risk of 
morbidity and mortality, obesity leads to various psychological stresses that vary from emotional distress to social stigmatization $[13,24]$.

Guadeloupe, a French overseas department, is distinguished by its population with a strong predominance of black subjects of African origin and socio-economic conditions different from those of the French metropolitan departments.

The global prevalence of diabetes is rapidly increasing, and in Gouadeloupe, the estimated prevalence of type 2 diabetes in adults rose from $5,8 \%$ in 1990 [17] to $8,6 \%$ in 2012. It is nearly twice as high as in France (4.7\%). The other overseas regions (Guyana, Martinique and Reunion) also have higher prevalence levels of diabetes being respectively $7.5 \%, 7.4 \%$ and $9.8 \%$ [14].

We have found it necessary to carry out an epidemiological study in the patients cohort of Guadeloupian diabetics because, no studies has been directly evaluated the rates of obesity in the diabetic population in Guadeloupe, this French Department of Overseas Territories. It is in this context that we conducted this study to determine the prevalence of obesity to adult diabetic patients by the body mass indices.

\section{Material and Methods}

This is a transversal and descriptive study conducted from November 2014 to October 2015 the Department of Endocrinology - Diabetology of the University Teaching Hospital of Pointe-à-Pitre (Guadeloupe-France). It involved 175 diabetic patients survive in endocrinology consultation for the period of the study.

The diagnosis of diabetes mellitus was defined by a higher fasting blood glucose or equal to $1,26 \mathrm{~g} / \mathrm{l}$ or by a Hba1c superior or equal to $6,5 \%$.

The following parameters: gender, age, educational level, socio-professional categories, personal history of smoking, alcohol, sports, family history of diabetes, obesity or hypertension were collected by examination.

The size and weight of each subject were measured in the morning with a person weighs NUKURA brand and a fathom designed graduated timber. The subject was feet-naked, standing vertically to the measurement of height and weight. The indicator used to assess body size is the body mass index
(BMI) which is the weight/height in square (in $\mathrm{kg} / \mathrm{m}^{2}$ in Table 1).

Blood pressure was measured in a person lying in dorsal recumbency for $05 \mathrm{~min}$ in the left arm sample size, method of data collection.

\subsection{Data Interpretation}

Table 1. Body Mass Indices BMI $\left(\mathrm{kg} / \mathrm{m}^{2}\right)$.

\begin{tabular}{lll}
\hline IMC & $\mathbf{( k g / \mathbf { m } ^ { \mathbf { 2 } }}$ & Interpretation \\
\hline Less than & 18,5 & Underweigh \\
Between & 18,5 and 24,9 & Normoweight \\
Between & 25 and 29,9 & Overweight \\
Superior or equal & 30 & Obesity \\
\hline
\end{tabular}

\subsection{Blood Pressure (BP)}

The subject with greater than or equal to TA $140 / 90 \mathrm{~mm}$ $\mathrm{Hg}$ was considered to have high blood pressure. Data were analyzed by the software SPSS12. $\mathrm{Khi}^{2}$ test and One-way ANOVA was used to compare means.

\section{Results}

Table 2. Characteristics of diabetic study population.

\begin{tabular}{llll}
\hline & Total & $\mathbf{H}$ & $\mathbf{F}$ \\
& $\mathbf{N = 1 7 5}$ & $\mathbf{N}=\mathbf{8 0}$ & $\mathbf{N = 9 5}$ \\
\hline Average age (year) & 60 & 57 & 54 \\
Average weight (kg) & 73,40 & 71,80 & 77,40 \\
Height (m) & 1,74 & 1,76 & 1,65 \\
Alcohol & 98 & 59 & 39 \\
Tobacco & 32 & 32 & 0 \\
Sport & 71 & 52 & 19 \\
Family obesity & 45 & 15 & 30 \\
\hline
\end{tabular}

We followed 175 diabetic patients during the study period. The average age of these patients was $60 \pm 10,9$ years.

By occupational category, there were 4 public works: engineers $19(10,8 \%), 25$ retired civil servants $(14,3 \%)$ and 50 housewives $(28,6 \%)$.

Other characteristics of the patients are described in Table 2. This table shows that there was a significant difference between men and women with diabetes about the characteristics described below.

Also taking into account the distribution of the study population by weight, the data are summarized in Table 3 .

Table 3. Distribution of the frequency of weight according to age groups.

\begin{tabular}{|c|c|c|c|c|c|c|c|c|}
\hline Sliced year & $\mathbf{N}$ & $\leq 45$ & $46-55$ & $56-65$ & $66-75$ & $76-85$ & $86-95$ & $\geq 96$ \\
\hline & & $\mathbf{N}(\%)$ & $\mathbf{N}(\%)$ & $\mathbf{N}(\%)$ & $\mathbf{N}(\%)$ & $\mathbf{N}(\%)$ & $\mathbf{N}(\%)$ & $\mathbf{N}(\%)$ \\
\hline Obesity & 76 & $0(0 \%)$ & $31(40,8 \%)$ & $18(23,6 \%)$ & $11(14,5 \%)$ & $7(9,2 \%)$ & $5(6,6 \%)$ & $4(5,2 \%)$ \\
\hline Over-weight & 12 & $0(0 \%)$ & $12(100 \%)$ & $0(0 \%)$ & $0(0 \%)$ & $0(0 \%)$ & $0(0 \%)$ & $0(0 \%)$ \\
\hline Normal weight & 80 & $12(15 \%)$ & $15(18 \%)$ & $14(17,5 \%)$ & $20(25 \%)$ & $8(10 \%)$ & $9(11,25 \%)$ & $2(2,2 \%)$ \\
\hline Thinness & 7 & $0(0 \%)$ & $0(0 \%)$ & $0(0 \%)$ & $0(0 \%)$ & $0(0 \%)$ & $2(28,5 \%)$ & $5(71,5 \%)$ \\
\hline Total & 175 & $12(6,9 \%)$ & $58(33,1 \%)$ & $32(18,28 \%)$ & $31(17,80 \%)$ & $15(8,57 \%)$ & $16(9,14 \%)$ & $11(6,28 \%)$ \\
\hline
\end{tabular}

This table shows in part a gradual increase in the incidence of obesity with age brackets. The peak of this growth is found between 46 and 55 years. On a total of 175 diabetic patients, 76 patients were obese and 12 overweight, giving a prevalence of $43,40 \%$ of obesity and $6,8 \%$ overweight.

Depending on gender, obesity was significantly more frequent in women $(60,5 \%)$ than men $(39,5 \%)$ with $\mathrm{P}<0.027$. 


\section{Discussion}

The study of obesity prevalence in Guadeloupe is critical to comment on the public health status, to determine the relevant health policies and obesity preventive procedures. Our study shows, of 175 adult diabetic patients who were followed, obesity was found in of $43,40 \%$. In consistent with these studies in $385,82,160$ type 2 diabetic patients which showed that the prevalence of obesity were respectively $4,2 \%, 11 \%, 14,4 \%[1,20,21]$. However, higher prevalence was reported in one of the study done, the majority $(83 \%)$ of the 212 type 2 diabetic patients were obese [7].

Age is the most important factor influencing the prevalence of obesity. The increasing rate of obesity among diabetics age between 46 to 55 was estimated as $40,8 \%$ and it decreased in those old; it was $14 \%$ in the age group of $66-75$ years and 5,2\% for more than 96 years (Table 3). This higher prevalence that is high up to 55 years and gradually decreases in the elderly could be possibly explained by weight loss occurring in old age [23]. That is why, prevalence of obesity frequency increases parallel with age, at least up to 50-60 years and over 70 years it is recording a decrease, in both men and women [19].

But, in other studies it's not. On a total of 385 patients diabetics between $40-49$ years, $50-59$ years then 60 years and more there are respectively $30,6 \%, 28,3 \%$ and $34,3 \%$ of obese [21]. And, in a cohort of 4098 diabetic patients between 45-54 years, 55- 64 years then 65 years and more there are respectively $20,1 \%, 29,4 \%$ and $40,6 \%$ of obese [28]. These two precedents studies in diabetic patients show that it is evidence of notable differences in the obesity prevalence rates among countries. The high prevalence of obesity in both studies especially in older age (60 and 65 years) can be a consequence of the decrease in daily physical activity and increased caloric intake of fast food products.

Regarding gender, there is a tendency of higher rates of obesity in women in that region of Guadeloupe. They were more affected by obesity than men, (39,5\%) against 60,5\%, $\mathrm{P}<0.027$ ) (Table 3). This prevalence of obesity in Guadeloupians women may be explained by high parity (average 3-4 children), unpracticed less physical activity (19 women against 52 men) and family obesity (30 women against men 15) [18, 19]. In fact, higher prevalence of obesity among females than males is a global phenomenon and had widely examined [22]. Obesity was also found to be significantly higher in married and Punjabi women [10]. The higher prevalence among Punjabi housewives in the age group of 40-60 years could be due to menopausal changes and high fat diet.

Otherwise, the prevalence of women obesity in our patients cohort $(60,5 \%)$ is more than which was observed among South African women, at $42 \%$ [15] and also in other study showed that higher percentage of the women $(67,82 \%)$ when compared to the male (43.1\%) [18].

Indeed, the weakness of physical activity especially in the women who have become more sedentary in their way of life, could explain the obesity rate markedly increased. To cope with obesity, exercise prevents excess weight and helps maintain weight loss [27]. The level of education and the level of income influence the risk of obesity, which is gradually becoming a marker of low living standards. It is argued that better education is associated with health literacy which might resulted in higher consumption of fruits and vegetables and lower consumption of fats [6].

The assertion of increase of level obesity peaks in our study is also verified. The peak of obesity is higher in our study (40,8\% between $46-55$ years) than in other studies $39,5 \%$ between $40-59$ years [15] and 36\% between 55-64 years) [9] in the United States of America although these peaks occur in different age groups. Clinical signs of obesity that reach peaks at some point may indicate difficulties in controlling the factors already cited as the physical activity. The significant increase in prevalence in the latter case is explained by many factors that are more pronounced and which can lead to energy imbalance and weight gain among the populations concerned. These include also poor diet, insufficient sleep, stress and income [3, 19]. The family obesity was $25,7 \%$ (Table 2). This level shows the difficulty in achieving and maintaining weight loss lies in genetic obesity by disrupts the function of hypothalamic integrative centers $[5,8]$.

The results of this study should be interpreted in light of some limitations. Although, ourself had collected data on weight and height, this cross- sectional design of the study limits us to examine changes in prevalence of obesity over time.

\section{Conclusion}

Our preliminary study showed a high prevalence of obesity in diabetic study population $(43,42 \%)$ and obesity is more prevalent in females than in males. This diabetic study population may therefore be at risk of developing obesity related health disorders. The frequency of this disease and its real cost are a major public health problem to push for government action in this French department where obesity should be taken into account in health policy measures.

\section{References}

[1] Basukala A, Sharma M, Pandeya A. Prevalence of overweight and obesity among patients with type 2 diabetes mellitus in Kathmandu. Sky J Biochem Res, 2014; 3(7): 60 -64.

[2] Bhupathiraju SN, Ju FB. Epidemiology of obesity and diabetes and their cardiovascular complications. Circulation Research. 2016; 118: 1723-1735.

[3] Bhurosy T, Jeewon R. Overweight and obesity epidemic in developing countries: A problem with diet, physical activity, or socioeconomic status? Sci World J, 2014; 1-7.

[4] Buse JB, Ginsberg HN, Bakris GL et al. Primary prevention of cardiovascular diseases in people with diabetes mellitus: a scientific statement from the American Heart Association and the American Diabetes Association. Diabetes Care, 2007; 30, 1: $162-172$. 
[5] Campbell LV. Genetics of obesity. AM, 2017; 46, 7: 456-459.

[6] Cha ES, Kim KH, Lerner HM, Dawkins CR, Bello MK and al. Health literacy, self-efficacy, food label use and diet in young adults. Am J Health Behav, 2014; 38 (3): 31-39.

[7] Fadupin GT, Joseph EU, Keshinro O. Prevalence of obesity among type 2 diabetics in Nigeria a case study of patients in Ibadan, Oyo State, Nigeria. Afr. J. Med. Med. Sci., 2004, 33(4): 381-4.

[8] Faith MS, Kral TVE. Social environmental and genetic influences on obesity and obesity-promoting behaviors: Fostering research integration. In: Hernandez LM, Blazer DG. Institute of Medicine (US) committee on assessing interactions among social, behavioral and genetic factors in health; Editors. Genes, Behavior and the Social Environment: Moving Beyond the Nature/Nurture Debate. Washington (DC): National Academies Press (US); 2006.350p.

[9] Flegal KM, Carroll MD, Kit BK, Ogden CL. Prevalence of obesity and trends in the distribution of body mass index among US adults, 1999-2010. J Am Med Ass, 2012; 307(5): 91-97.

[10] Girdhar S, Sharma S, Chaudhary A, Bansal P and Satija M (2016). An epidemiological study of overweight and obesity among women in an urban area of North India. Indian J Community Med, 2016, 41(2): 54-57.

[11] HAS. Overweight and obesity in adults: first-line medical care. www.has - santé.fr; 2011.

[12] Iciar-Timón M, Sevillano-Collantes C, Cañizo-Gómez FJ. Type 2 diabetes and cardiovascular disease: have all risk factors the same strength? World J Diabetes, 2014; 15, 5(4): 44-70.

[13] Jonikas AJ, Cook JA, Razzano LA, Steigman PJ, Hamilton $\mathrm{MM}$ and al. Associations between gender and obesity among adults with mental illnesses in a community health screening study. Community Ment Health J, 2016; 52: 406-415.

[14] Mandereau-Bruno L, Denis P, Fagot-Campagna A, FosseEdorh S. Prévalence du diabète traité pharmacologiquement et disparités territoriales en France en 2012. Bull Epidémiol Hebd. 2014; (30-31): 493-9.

[15] Marie Ng, Fleming T, Robinson M, Thomson B, Graetz N, Margono $C$ and al (2014). Global, regional, and national prevalence of overweight and obesity in children and adults during 1980-2013: a systematic analysis for the Global burden of disease study. 2013, 384, (9945): 66-81.

[16] Merlotti C, Morabito A and Pontiroli AE. Prevention of type 2 diabetes; a systematic review and meta-analysis of different intervention strategies. Diabetes, Obesity and Metabolism, $2014 ; 16,8,719-727$.
[17] Moutet JP, Kangambega-Nouvier P, Donnet JP, Pileire B, Eschvege $\mathrm{E}$ and al. Diabetes mellitus and public health in Guadeloupe. West Indian Med J, 1990; 39(3): 139-143.

[18] Olebu J, Ajaebili NA, Maduforo AN. Assessment of prevalence of obesity among newly diagnosed type 2 diabetic patients in diabetic out patient clinic, of university of Nigeria Teaching Hospital (UNTH), Ituku/Ozalla, Enugu State, Nigeria. Advances Life Sci-Technol, 2014; 24: 60-66.

[19] Obirikorang Y, Obirikorang C, Anto EO, Acheampong E, Dzah N and al. Knowledge and lifestyle-associated prevalence of obesity among newly diagnosed type 2 diabetes mellitus patients attending diabetic clinic at Komfo Anokye teaching hospital, Kumasi, Ghana: a hospital-based cross-sectional study. J Diabetes Res. 2016; 2016: 975924.

[20] Pandeya A, Sharma M, Regmi P, Basukala A and Lamsal M. Pattern of dyslipidemia and evaluation of non-HDL cholesterol as a marker of risk factor for cardiovascular disease in type 2 diabetes mellitus. Nepal Med. Coll. J., 2012 14(4): 278-282.

[21] Parajuli J, Swar NB, Khadka D, Thapa N. Prevalence of Obesity Among Type 2 Diabetes Patients Attending Diabetic Clinic in Nepalgunj Medical College Teaching Hospital. JNMC, 2014; 1, 25-28.

[22] Pudrovska T, Reither EN, Logan ES, Kyler J. ShermanWilkins. Gender and reinforcing associations between socioeconomic disadvantage and body mass over the life course. JHSB, 2014; 55(3): 283-301.

[23] Ringbäck WG, Eliasson M, Rosen M. Underweight, overweight and obesity as risk factors for mortality and hospitalization. Scand J Public Health. 2008; 36 (2): 69-76.

[24] Visscher TLS, Seidell JC. The public health impact of obesity. Ann Rev Public Health, 2001; 22: 355-375.

[25] World Health Organization, Global Health Risks: Mortality and Burden of Disease Attributable to Selected Major Risk, World Health Organization, Geneva, Switzerland, 2009; 70p.

[26] World Health Organization. Obesity and overweight, Fact sheet, 2017; n³11.

[27] Wiklund P. The role of physical activity and exercise in obesity and weight management: Time for critical appraisal. J of sport and health sci. 2016; 5 (2) 51-54.

[28] Zhou X, Ji L, Ran X, Su B, Ji Q, Pan C, et al. (2016) Prevalence of Obesity and Its Influence on achievement of cardiometabolic therapeutic goals in Chinese type 2 diabetes patients: An analysis of the nationwide, cross-sectional 3B study. Plos One, 2016; 11(1): e0144179. 